2015-01-01

\title{
Factors Affecting the Clinical Use of Non-Invasive Prenatal Testing
}

\author{
Skirton, $\mathrm{H}$
}

http://hdl.handle.net/10026.1/5182

10.4172/2376-0311.1000121

JBR Journal of Clinical Diagnosis and Research

OMICS Publishing Group

All content in PEARL is protected by copyright law. Author manuscripts are made available in accordance with publisher policies. Please cite only the published version using the details provided on the item record or document. In the absence of an open licence (e.g. Creative Commons), permissions for further reuse of content should be sought from the publisher or author. 


\section{Factors Affecting the Clinical Use of Non-Invasive Prenatal Testing}

Heather Skirton ${ }^{1^{*}}$ and Leigh Jackson ${ }^{2}$

${ }^{1}$ Applied Health Genetics, Faculty of Health and Human Sciences, Plymouth University, UK

${ }^{2}$ Faculty of Health and Human sciences, Plymouth University, Plymouth, UK

*Corresponding authors: Skirton H, Drake Circus, Plymouth, PL4 8AA, UK, E-mail: Heather.skirton@plymouth.ac.uk

Received date: May 15, 2015; Accepted date: September 01, 2015; Published date: September 03, 2015

Copyright: (C) 2015 Skirton $\mathrm{H}$, et al. This is an open-access article distributed under the terms of the Creative Commons Attribution License, which permits unrestricted use, distribution, and reproduction in any medium, provided the original author and source are credited.

\section{Introduction}

Non-invasive prenatal testing (NIPT) is a technique first developed in the early 1990's that enables testing of a fetus for genetic conditions, based on a sample of maternal blood [1]. Small fragments of extracellular DNA from both mother and fetus are present in maternal plasma, and by excluding fragments of maternal origin, the fetus can be tested for sex, aneuploidy and some specific genetic conditions [2]. The main benefits of this type of fetal testing over amniocentesis or chorionic villus sampling are the removal of any risk of miscarriage due to invasive testing and obtaining results in the first trimester [2].

There are some differences in the contexts in which NIPT can be used to determine the chance of the fetus being affected by a genetic condition. In some families, there is a known genetic condition that could be inherited by the fetus. Examples of this type of condition are cystic fibrosis and achondroplasia [short-limbed dwarfism). In these families, the genetic mutation is usually known of before pregnancy and the prospective parents may have been considering prenatal testing for some time. In a different context, pregnant women may be offered NIPT for aneuploidy (including trisomy 21). All women in the general population have a chance of having a fetus affected by trisomy 21 , and testing may therefore be offered on a population basis. Women in this group may not have ever considered fetal testing prior to being informed about it by the health professional involved in their care during pregnancy. The extent to which prenatal testing had been considered prior to pregnancy could seriously influence the level of informed consent for the test.

In a review of factors affecting the use of NIPT [3], overall both patients and professionals viewed the use of NIPT positively. Women felt it empowered them to have testing without the threat of miscarriage, and the earlier result enabled them to have a termination at an earlier stage in the pregnancy. However, there were concerns expressed that the ease of giving a sample might influence women to have tests for reasons that the participants felt were not justified. Moral and ethical concerns about increased use of testing and termination were more likely to be expressed by those in the general population who had not necessarily considered the test in a personal context. However, it was noticeable that in most studies the views of men, particularly prospective fathers, were not sought.

These issues were examined in detail in a recent study of men and women who were carriers of autosomal recessive conditions [4]. All of the participants were at risk of having a child with a serious genetic condition: many of them had affected children or had lost children or pregnancies. In that study, there was again support for the use of NIPT, for many of the same reasons unearthed in the systematic review. However, participants emphasised that even if the test was easy, it was the results that had to be dealt with. They believed that making decisions (about the future of the pregnancy) based on those results could be very difficult and some people accepting the test may not appreciate that. They also felt that while it was ultimately the woman's decision to have the test, both parents should be involved in such an important and potentially life-changing process.

The 'take home' message from the research is that while there are considerable benefits accruing from the development of NIPT, health professionals have a duty to ensure that informed consent is given, and this involves having a conversation about the impact of the results and potential decisions to be made, based on those results The responsibility for offering these types of tests will lie with different groups of health professionals, depending on the purpose of the test and the health service structure in each country. For example, tests for single gene disorders where the fetus is known to be at high risk (usually $25 \%$ or $50 \%$ chance of being affected, depending on the disorder) will often be discussed by specialist in genetic services, either medical geneticists or genetic counsellors or by fetal medicine specialists. These professionals have extensive experience at offering prenatal tests in a non-directive manner. However, it may be that tests for aneuploidy are offered by midwives, obstetricians or family practitioners, in which case they may have less experience in this context. In fact, previous research has shown that many midwives lack the confidence and knowledge to offer prenatal screening for trisomy 21[5]. There must therefore be concern about the ability of health professionals to offer NIPT to prospective parents in a way that informs them appropriately and enables them to make informed decisions. It is important that parents recognise that they have a choice to decline testing or to accept testing to prepare themselves for the birth of an affected baby. Testing should not be framed simply as a route to termination of an affected pregnancy, although this is a decision that will be the most appropriate one for some parents.

We would suggest that the conversation about NIPT should include key information about the test, the possibility of false negative or false positive results and, where relevant, the possible need for an invasive test to confirm the diagnosis. However, in addition, parents should be forewarned about the possible implications of the results. One way in which this can be done is to ask parents to try to consider their potential reactions to both types of possible results: a result indicating there is minimal risk of the fetus being affected and a result showing there is a very high likelihood that the fetus is affected. The question' What do you think your options might be, based on a high risk result?' may help to clarify why they are doing the test and their possible reactions to the outcome. By making the possible outcomes more concrete for parents, the health professional can facilitate them to consider the test and the result in the context of their own beliefs and values.

Non-invasive prenatal testing has the potential to benefit a great many parents who wish to find out more about the genetic status of their fetus but wish to minimise any risks involved in testing. It is 
Citation: Skirton H, Jackson L (2015) Factors Affecting the Clinical Use of Non-Invasive Prenatal Testing. J Clin Diagn Res 3: 121. doi: 10.4172/2376-0311.1000121

Page 2 of 2

essential that policies regarding NIPT are put in place to guide both parents and health professionals, and that discussion of the ethical issues occurs at societal level. Increasing public awareness of this type of testing will help to prepare prospective parents for decision-making, but ultimately health professionals have a duty to ensure that they are able to consider both the short and long term implications of any decision they make.

\section{References}

1. Lo YMD (1994) Noninvasive Prenatal-Diagnosis Using Fetal Cells In Maternal Blood. J Clin Pathol 47: 1060-1065.
2. Hill M, Barrett AN, White H, Chitty LS ( 2012) Uses of cell free fetal DNA in maternal circulation. Best Pract Res Clin Obstet Gynaecol 26: 639-654.

3. Skirton H, Patch C (2013) Factors affecting the clinical use of noninvasive prenatal testing: a mixed methods systematic review. Prenatal Diagnosis 33: 532-541.

4. Skirton H, Goldsmith L, Chitty LS (2014) An easy test but a hard decision: ethical issues concerning non-invasive prenatal testing for autosomal recessive disorders. Eur J Hum Genet 23: 1004-1009.

5. Barr O, Skirton H (2013) Informed decision making regarding antenatal screening for fetal abnormality in the United Kingdom: A qualitative study of parents and professionals. Nurs Health Sci 15: 318-325. 